\title{
Effects of Chilling on the Structure, Function and Development of Chloroplasts
}

\author{
Xiaomin Liu' ${ }^{1}$, Yunlin Zhou' ${ }^{1}$, Jianwei Xiao ${ }^{1}$ and Fei Bao ${ }^{2 *}$ \\ ${ }^{1}$ College of Biological Sciences and Biotechnology, Beijing Forestry University, Beijing, China, ${ }^{2}$ Beijing Key Laboratory \\ of Ornamental Plants Germplasm Innovation \& Molecular Breeding, National Engineering Research Center for Floriculture, \\ Beijing Laboratory of Urban and Rural Ecological Environment, Engineering Research Center of Landscape Environment \\ of Ministry of Education, Key Laboratory of Genetics and Breeding in Forest Trees and Ornamental Plants of Ministry \\ of Education, School of Landscape Architecture, Beijing Forestry University, Beijing, China
}

OPEN ACCESS

Edited by:

Benoit Schoefs,

The University of Maine, France

Reviewed by:

Aron Keresztes,

Eötvös Loránd University, Hungary Agnieszka Mostowska,

University of Warsaw, Poland

*Correspondence:

Fei Bao

baofei@bjfu.edu.cn

Specialty section:

This article was submitted to Plant Physiology,

a section of the journal

Frontiers in Plant Science

Received: 29 June 2018 Accepted: 05 November 2018 Published: 22 November 2018

Citation:

Liu X, Zhou Y, Xiao J and Bao F (2018) Effects of Chilling on the Structure, Function and Development of Chloroplasts. Front. Plant Sci. 9:1715.

doi: 10.3389/fpls.2018.01715
Chloroplasts are the organelles that perform energy transformation in plants. The normal physiological functions of chloroplasts are essential for plant growth and development. Chilling is a common environmental stress in nature that can directly affect the physiological functions of chloroplasts. First, chilling can change the lipid membrane state and enzyme activities in chloroplasts. Then, the efficiency of photosynthesis declines, and excess reactive oxygen species (ROS) are produced. On one hand, excess ROS can damage the chloroplast lipid membrane; on the other hand, ROS also represent a stress signal that can alter gene expression in both the chloroplast and nucleus to help regenerate damaged proteins, regulate lipid homeostasis, and promote plant adaptation to low temperatures. Furthermore, plants assume abnormal morphology, including chlorosis and growth retardation, with some even exhibiting severe necrosis under chilling stress. Here, we review the response of chloroplasts to low temperatures and focus on photosynthesis, redox regulation, lipid homeostasis, and chloroplast development to elucidate the processes involved in plant responses and adaptation to chilling stress.

Keywords: chilling, chloroplasts, development, chloroplast structure, ROS, photosynthesis

\section{INTRODUCTION}

Chloroplasts develop from proplastids under different leaf development contexts in monocots and dicots. Chloroplasts have a double membrane envelope that encloses the stroma and thylakoids. As plant organelles, chloroplasts are sensitive to changes in environmental conditions, and they can react quickly - within a few minutes - by movement. Chloroplasts are the exclusive sites of photosynthesis and capture light energy from the sun to produce chemical energy. Moreover, chloroplasts are involved in many other metabolic pathways, including the synthesis of lipids, pigments, plant hormones, and numerous other metabolites. Plants need to maintain a steadystate balance between energy generation and consumption (Suzuki et al., 2012). Once this balance is destroyed, oxidative stress can be induced in cells by promoting the generation and accumulation of reactive oxygen species (ROS), such as singlet oxygen $\left({ }^{1} \mathrm{O}_{2}\right)$, superoxide anion radicals $\left(\mathrm{O}_{2}{ }^{-}\right)$, hydrogen peroxide $\left(\mathrm{H}_{2} \mathrm{O}_{2}\right)$, and hydroxyl radicals (Takahashi and Asada, 1988; Mittler, 2002; Takahashi and Murata, 2008; Miller et al., 2010). For example, limiting $\mathrm{CO}_{2}$ fixation by drought, 
salt or temperature stress can enhance the production of ROS (Mittler et al., 2004). Chloroplasts are a major sites for the production of ROS (Mignolet-Spruyt et al., 2016). ROS cause the oxidation of cellular components, interfere with metabolic activities and affect chloroplast integrity. Plants have developed many strategies to address these phenomena and maintain suitable photosynthetic efficiency. These processes involve a complex chain of redox reactions and the reactive oxygen scavenging system.

Low temperatures, also called chilling, refer to low, but not freezing, temperatures $\left(0-15^{\circ} \mathrm{C}\right)$ (Theocharis et al., 2012; Wang S. et al., 2016). Low temperatures can affect plant growth during each stage of life from germination to maturity and limit the distribution of plants throughout the world. Different plants have different capacities to tolerate chilling stress. Many tropical and subtropical plants, including tobacco, rice and maize, cannot survive at chilling temperatures, whereas Arabidopsis and some overwintering cereals can continue to grow (Stitt and Hurry, 2002; Wang S. et al., 2016). Early studies reported that a series of physiological and cellular changes occur in plants under chilling conditions, including alterations in the membrane structure, photosynthesis, calcium signals, and metabolism (Lyons, 1973; Theocharis et al., 2012). These changes facilitate plant adaptation to chilling.

Chloroplasts, which are the sites of photosynthesis, can sense low temperatures and are the first and most severely affected organelles in plants (Lee et al., 2007). Chilling affects chloroplast function by inhibiting photosynthesis, inducing changes in the organelle's ultrastructure, and regulating chloroplast development (Tokuhisa et al., 1998; Kutik et al., 2004; Liu et al., 2008; Duan et al., 2012). Accumulating evidence suggests that the processes responsible for stabilizing and repairing photosynthetic proteins in response to chilling stress are present in plants to maintain the normal physiological function of chloroplasts. Some mutant plants with defects in the synthesis of some photosynthetic proteins exhibit a variety of symptoms, including variegated or pale leaves and growth suppression under chilling stress (Liu et al., 2010; Kong et al., 2014; Morita et al., 2017; Sun et al., 2017). Here, we summarize the impacts of low temperatures on chloroplasts in four sections, including photosynthesis, redox systems, chloroplast structure and development, and we discuss the response and adaptation of plants to chilling stress.

\section{EFFECTS OF CHILLING ON THE PHOTOSYNTHESIS SYSTEM IN CHLOROPLASTS}

The response of chloroplasts to low temperatures greatly depends on the ability of photosynthesis to sense chilling (Pfannschmidt, 2003). It's reported that both membrane and photoreceptors can perceive the change of temperature. The photosynthetic system complexes are located in the thylakoid membrane. Low temperatures can rigidify the thylakoid membrane and slow enzymatic reactions, thereby affecting the activity of the photosynthetic system. The membrane phase under chilling stress largely depends on the lipid composition. Thus, the lipid composition in the membrane of chloroplasts is very important for maintaining plant photosynthesis under low temperatures (which will be described in detail in the third section). Recent studies have reported that the photoreceptor phyB and phototropins act as thermosensory molecules that perceive fluctuating ambient temperatures (Jung et al., 2016; Legris et al., 2016; Fujii et al., 2017). Phototropin 2, a blue light receptor, was found to direct the position of chloroplasts to optimize photosynthesis in cold-avoidance response (Kodama et al., 2008). The effects of low temperatures on photosynthesis mainly include the occurrence of photoinhibition and a reduction in the activity of some enzymes in the Calvin cycle. Low temperatures have been reported to cause thylakoids to uncouple in chilling-sensitive plants, and the H-ATPase is the site of damage (Peeler and Naylor, 1988; Terashima et al., 1989, 1991a,b). These studies imply that chilling can induce a series of physiological and biochemical events in chloroplasts, and both photoreceptors and membrane can perceive the temperature. It would be interesting to investigate how sensors deliver low-temperature signals to downstream factors.

Photoinhibition is a light-induced reduction in the photosynthetic capacity of chloroplasts in plants. Hodgson et al. (1987) described photoinhibition in plants at low temperatures as chill-induced photoinhibition or chilltemperature photoinhibition. Photoinhibition is an important event that occurs under chilling stress; thus, photoinhibition has been extensively examined by many researchers. First, researchers observed PSII damage following a low temperature treatment (Kaniuga and Michalski, 1978; Kaniuga et al., 1979; Shen et al., 1990). Shen et al. (1990) reported that under cold and dark conditions, electron transport on the oxidizing side of PSII was inactivated, which was ascribed to the degradation of extrinsic proteins and a decrease in the manganese content of PSII. The photodamage and repair occurred simultaneously. Chill-induced photoinhibition is partially determined by the effect of temperature on the recovery process, which involves the synthesis of some chloroplast-encoded proteins, notably, the D1 component at the core of the PSII functional center (Greer et al., 1986). Chilling interferes with the normal replacement rate of D1 in the turnover-repair cycle, which results in more serious photodamage (Allen and Ort, 2001). In tomato, the expression of the coding gene of D1 is regulated by SlWHY1, which is significantly induced by chilling (Zhuang et al., 2018). For a long time, scientists believed that PSII was the main component of photoinhibition. However, the photoinhibition of PSI was first reported in 1994 (Terashima et al., 1994). The chilling treatment of cucumber leaves under weak light destroyed $\mathrm{F}_{\mathrm{X}}$, $\mathrm{F}_{\mathrm{A}}, \mathrm{F}_{\mathrm{B}}$ and possibly the phylloquinone $\mathrm{A}_{1}$ in the iron-sulphur centers of PSI (Sonoike et al., 1995). Several studies have shown that PSI photoinhibition occurs under low temperature and weak light conditions and that the chilling-induced damage to PSI is irreversible, which may explain the irreversible damage to photosynthesis caused by low temperatures (Tjus et al., 1998; Teicher et al., 2000; Kudoh and Sonoike, 2002; Zhang and Scheller, 2004; Zhang et al., 2014). However, the chilling-induced photoinhibition of PSI could be alleviated by moderating the activity of PSII (Huang et al., 2016). Photoinhibition is an 
important self-protective mechanism in the chloroplast to reduce ROS production under low temperature conditions. The photoinhibition of PSII may minimize damage to PSI by decreasing the electron flow to PSI and maintaining PSI in an oxidized state. The photoinhibition of PSI may also be favorable for preventing overreduction on the electron acceptor side.

The rate of $\mathrm{CO}_{2}$ assimilation is also reduced under chilling stress. The reductive activation of two key carbon reduction cycle enzymes, fructose-1,6-bisphosphatase (FBPase) and sedoheptulose-1,7-bisphosphatase (SBPase), has been reported to substantially decrease under light-chilling conditions (Sassenrath et al., 1990; Kingston-Smith et al., 1997; Hutchison et al., 2000). The activity of ribulose-1,5-bisphosphate carboxylase/oxygenase (Rubisco) also declines under low temperature conditions. Chilling may damage the Rubisco protein or affect the redox regulation of the larger Rubisco activase isoform (Byrd et al., 1995; Kingston-Smith et al., 1997; Zhang and Portis, 1999). To acclimate to low temperatures, higher amounts of photosynthetic enzymes, such as the enzymes involved in the photosynthetic carbon reduction cycle and sucrose synthesis, are synthesized to compensate for the reduced activities of other enzymes, including Rubisco, SBPase, stromal FBPase, sucrose phosphate synthase and cytosolic FBPase, under chilling stress (Guy et al., 1992; Holaday et al., 1992; Hurry et al., 1994; Strand et al., 1997, 1999; Savitch et al., 2001). Thus, after plants are exposed to low temperatures for a given period of time, photosynthesis shows strong recovery.

\section{EFFECTS OF LOW TEMPERATURES ON THE REDOX STATE IN CHLOROPLASTS}

Low temperatures that reduce the activities of the photosynthesis system strike a balance between the light and dark reactions of photosynthesis and cause the production of excess electrons in transport chains. These excess electrons are released via transfer to oxygen to produce ROS, which induce oxidative stress and damage. Therefore, ROS-scavenging mechanisms, such as the release of superoxide dismutase (SOD) and the glutathioneascorbate cycle, are very important for maintaining normal function in chloroplasts under chilling stress. The levels of ROS and the activities of ROS-scavenging enzymes have been shown to increase in chloroplasts from plants grown under chilling stress conditions (Kaniuga et al., 1979; Choi et al., 2002; Hu et al., 2008). Zhou et al. (2006) reported that a chilling-tolerant cucumber cultivar had higher $\mathrm{H}_{2} \mathrm{O}_{2}$-scavenging activity in chloroplasts than a chilling-sensitive cultivar under low temperature conditions. Manipulation of the antioxidative mechanism in chloroplasts can change the tolerance to chilling stress in transgenic plants. Overexpressing both CuZnSOD and ascorbate peroxidase (APX) in the chloroplasts of transgenic plants enhanced plant tolerance to high light and chilling stress (Kim et al., 2003; Lim et al., 2007). Jing et al. (2006) identified a gene encoding a chloroplast-localized peroxiredoxin Q, SsPrxQ, in Suaeda salsa L. The overexpression of SsPrxQ in Arabidopsis enhanced plant tolerance to low temperatures. Decreased chloroplast glutathione reductase $(G R)$ gene expression in antisense transgenic plants resulted in chilling sensitivity (Shu et al., 2011; Ding et al., 2012). These studies illustrate that maintaining homeostasis in the redox state in chloroplasts is very important for plants under low temperature conditions. More highly active oxygenscavenging activities in plants may be due to greater tolerance to chilling stress. An altered redox state in chloroplasts due to various treatments, including methyl jasmonate, melatonin, brassinosteroid and acetylsalicylic acid, can affect plant tolerance to low temperatures ( $\mathrm{Li}$ et al., 2012; Wu et al., 2015; Zhao et al., 2016; Soliman et al., 2018). In wheat, mechano-stimulation applied during the growth period activated the antioxidant system, maintained the homeostasis of ROS, and improved electron transport and photosynthesis rates in plants exposed to chilling stress during the jointing stage (Li et al., 2015).

Although ROS are typically regarded as toxic to cells and can induce damage to chloroplasts via peroxidation of the membrane, inactivation of enzymes and degradation of proteins, ROS are also considered secondary messengers that regulate diverse functions, such as growth, development, and stress responses, in plants (Foreman et al., 2003; Laloi et al., 2004; Foyer and Noctor, 2005; Pitzschke et al., 2006; Miller et al., 2008; Foyer and Noctor, 2009; van Buer et al., 2016). As signals, ROS can regulate the expression of chloroplast and nuclear genes that repair damage due to chilling (which is described in the fourth section). Currently, ROS signaling pathways have not yet been completely unraveled. Some redox-sensitive transcription factors, such as NPR1 and HSFs, may participate in perceiving these signals (Mou et al., 2003; Fedoroff, 2006). Laloi et al. reported that ROS signals may regulate the expression of antioxidant genes by activating the MAPK cascade (Laloi et al., 2004).

\section{EFFECTS OF LOW TEMPERATURES ON THE STRUCTURE OF THE CHLOROPLAST MEMBRANE}

Lipid composition is considered to be closely related to chilling tolerance. Phosphatidylglycerol (PG) is the main component of the membrane, and it is crucial for the photosynthetic process in chloroplasts (Somerville, 1995; Wu et al., 1997; Routaboul et al., 2000). The phase of the membrane is affected by temperature and depends on the extent of the unsaturation of fatty acyl chains. The genetic manipulation of fatty acid (FA) unsaturation has been shown to alter the sensitivity of transgenic plants to chilling (Murata et al., 1992). Levels of unsaturated FAs are regulated by FA-desaturase (FAD) activities (D'Angeli and Altamura, 2016). Researchers have found that the extent of the unsaturation of FAs in PG in the thylakoid membrane can protect the photosynthesis system against chilling-induced photoinhibition (Moon et al., 1995; Liu et al., 2008). Galactolipase, which is responsible for the degradation of membrane lipids, is significantly active in chilling-sensitive plants at low temperatures, and then results in the increase of free FA in chloroplasts (Kaniuga, 2008). Additionally, monogalactosyldiacylglycerols (MGDGs), digalactosyldiacylglycerol (DGDG), sulphoquinovosyldiacylglycerols (SQDGs) and phosphatidylcholine (PC) are major lipids in the thylakoid 
membrane (Pribil et al., 2014; Li and Yu, 2018). Chilling alters the compositions of galactolipid and carotenoid; in particular, chilling causes a reduction in the levels of MGDGs and SQDGs and an increase in lutein. Furthermore, chilling induces the transition of prolamellar body structures from the compacted "closed" type to the looser "open" type in cucumber and tomato, resulting in decreased membrane fluidity (Novitskaya and Trunova, 2000; Degenkolbe et al., 2012; Skupień et al., 2017). In tobacco, following exposure to $8^{\circ} \mathrm{C}$ for several days, the relative levels of unsaturated FAs, mainly $18: 3 n-3$ FA, in chloroplast envelopes and thylakoids were significantly elevated, which altered membrane fluidity to accommodate the high-level functioning of the photosynthetic apparatus (Peoples et al., 1978; Sakamoto et al., 2004; Khodakovskaya et al., 2006; Popov et al., 2017). As mentioned above, the presence of high levels of unsaturated FAs in chloroplasts increases the tolerance of plants to chilling (Cronan and Roughan, 1987; Murata et al., 1992). Furthermore, upon exposure to chilling, total FAs are increased, phospholipids are preferentially synthesized and the unsaturation degree of DGDG increases in some plants (Saczynska et al., 1993; Partelli et al., 2011; Scotti-Campos et al., 2014; Gu et al., 2017). Lipids have selective distributions in subcellular organelles, membrane leaflets and membrane domains. The lipid composition has a profound impact on the physical properties of membranes. Once lipid homeostasis is lost, corresponding membrane functions and chloroplast morphology are affected.

The chloroplast ultrastructure is also an important factor that is responsible for the functions of chloroplasts under chilling conditions (Wu and Browse, 1995; Chen and Thelen, 2013). Under cold stress, the size and number of chloroplasts have been shown to rapidly increase in wheat, and the length of the photosynthetic membrane and the number of thylakoids have been shown to increase in grana (Venzhik et al., 2014, 2016). Different degrees of low temperatures lead to different degrees of change in the chloroplast ultrastructure in maize, including changes in the volume densities of granal and intergranal thylakoids, plastoglobules, and peripheral reticulum and dimensions (Kutik et al., 2004; Saropulos and Drennan, 2007; Hola et al., 2008). Generally, in chilling-sensitive plants, the initial manifestations of chilling injury mainly include the swelling of chloroplasts and thylakoids and an increase in plastoglobule numbers (Musser et al., 1984; Zbierzak et al., 2013; Karim et al., 2014). Over time, a series of symptoms emerge, including darkening of the stroma, unstacking of the grana, disintegration of the thylakoid membranes and the chloroplast envelope, vesicle accumulation, and chloroplast disintegration (Musser et al., 1984; Kratsch and Wise, 2000; Zbierzak et al., 2013; Karim et al., 2014). In chilling-resistant plants, starch granules continue to decrease over time and finally disappear (Kratsch and Wise, 2000; Zhuang et al., 2018), and more condensed grana disks are present (Garstka et al., 2007). As time increases, a cold acclimation process is initiated, and a broad range of responses contribute to the adaptation of plants to chilling stress. The above-mentioned symptoms are closely related to the accumulation of ROS, the rigidity of membranes and a profound reprogramming of nuclear and chloroplast-encoded gene expression. However, the underlying mechanism that modulates the presence of these symptoms is largely unclear.

\section{EFFECTS OF CHILLING ON CHLOROPLAST DEVELOPMENT}

During chloroplast development, the number, size and composition of plastids change (Mullet, 1988). Chilling is an adverse environmental signal that alters processes, such as pigment synthesis, light-energy absorption, and photosynthetic electron transport, inducing changes in the redox state of photosynthesis components and the accumulation of ROS (Gong et al., 2014; Wu et al., 2016; Morita et al., 2017). Some regulatory factors, including ROS, influence various activities, including multiple chloroplast RNA processing steps, ribosome loading and protein translation, further affecting larger sets of chloroplast transcripts and regulating the expression of chloroplast and nuclear genes (Pfannschmidt, 2003; Kupsch et al., 2012; Exposito-Rodriguez et al., 2017). C-repeat/DREB binding factors (CBFs), which act as act as master transcription factors, are rapidly induced within 15 min during chilling stress and in turn activate the expression of a large number of downstream cold responsive (COR) genes (Chinnusamy et al., 2007; Zhu, 2016; Shi et al., 2018). CBF3 and COR genes are sensitive to the redox state of chloroplasts (Kurepin et al., 2013). Moreover, the expression of some COR genes is regulated by CBF-independent transcription factors (Shi et al., 2018), such as RNA-binding domain 1 (RBD1) (Wang S. et al., 2016). These changes in chloroplasts are communicated to the nucleus through retrograde signals, including singlet oxygen (Lee et al., 2007; Kim et al., 2012; Mullineaux et al., 2018) and methylerythritol cyclodiphosphate (MEcPP) (Xiao et al., 2012), in Arabidopsis thaliana and $\mathrm{H}_{2} \mathrm{O}_{2}$ in Nicotiana benthamiana (Exposito-Rodriguez et al., 2017). Retrograde-signaling molecules further activate a broad range of responses and elicit the expression of stress-responsive nuclearencoded proteins. There may be multiple retrograde signals from chloroplast to nucleus involving in chilling stress and they may work together in plant.

These regulatory mechanisms facilitate the repair and regeneration of proteins damaged by chilling to maintain the normal physiological functions of chloroplasts. Higher chillingtolerant plants have stronger repair abilities. In chilling-resistant plants, chloroplast development is retarded (Humbeck et al., 1994). In chilling-sensitive plants, cool temperatures promote cool-temperature-induce-chlorosis (CTIC) symptoms in newly emerging leaves or result in different degrees of an albino phenotype (Song et al., 2014; Wu et al., 2016). Various RNAbinding proteins (RBPs), including pentatricopeptide repeat protein (PPR) and ribonucleoproteins (RNPs), are needed for the response to chilling stress to maintain chloroplast development. The loss of $R B P$ genes results in yellow or bleached leaves, and some mutants even exhibit delayed seed germination accompanied by pale primary leaves (Kusumi et al., 2011; Kupsch et al., 2012; Gong et al., 2014; Song et al., 2014; Xu et al., 2014; Wang S. et al., 2016; Wu et al., 2016; Zhang et al., 2016; Cui et al., 2018). Moreover, the transcription levels of genes associated 
with chlorophyll biosynthesis, photosynthesis and chloroplast development are altered by chilling (Gong et al., 2014; Wu et al., 2016). Some proteins have been reported to influence the development of chloroplasts by disturbing photosynthetic electron transfer, regulating the transcript levels of genes involved in chloroplast transcription/translation and photosynthesis and interfering with RNA processing (Liu et al., 2010; Gu et al., 2014; Wang Y. et al., 2016; Morita et al., 2017). Mutations in these genes result in a deficiency in chlorophyll synthesis that causes chlorotic, white or dead leaves to varying degrees at low temperatures, and some mutations even cause severe growth inhibition, such as the temperature-sensitive chlorophylldeficient rice mutant tcd5 (Liu et al., 2010; Gu et al., 2014; Wang Y. et al., 2016; Morita et al., 2017). The decrease in chlorophyll content will further affect the ability of chloroplasts to capture light signals. Furthermore, some metabolites, such as sucrose, trehalose, vitamin E etc., are demonstrated to have a protective function for chloroplasts under chilling conditions. Arabidopsis

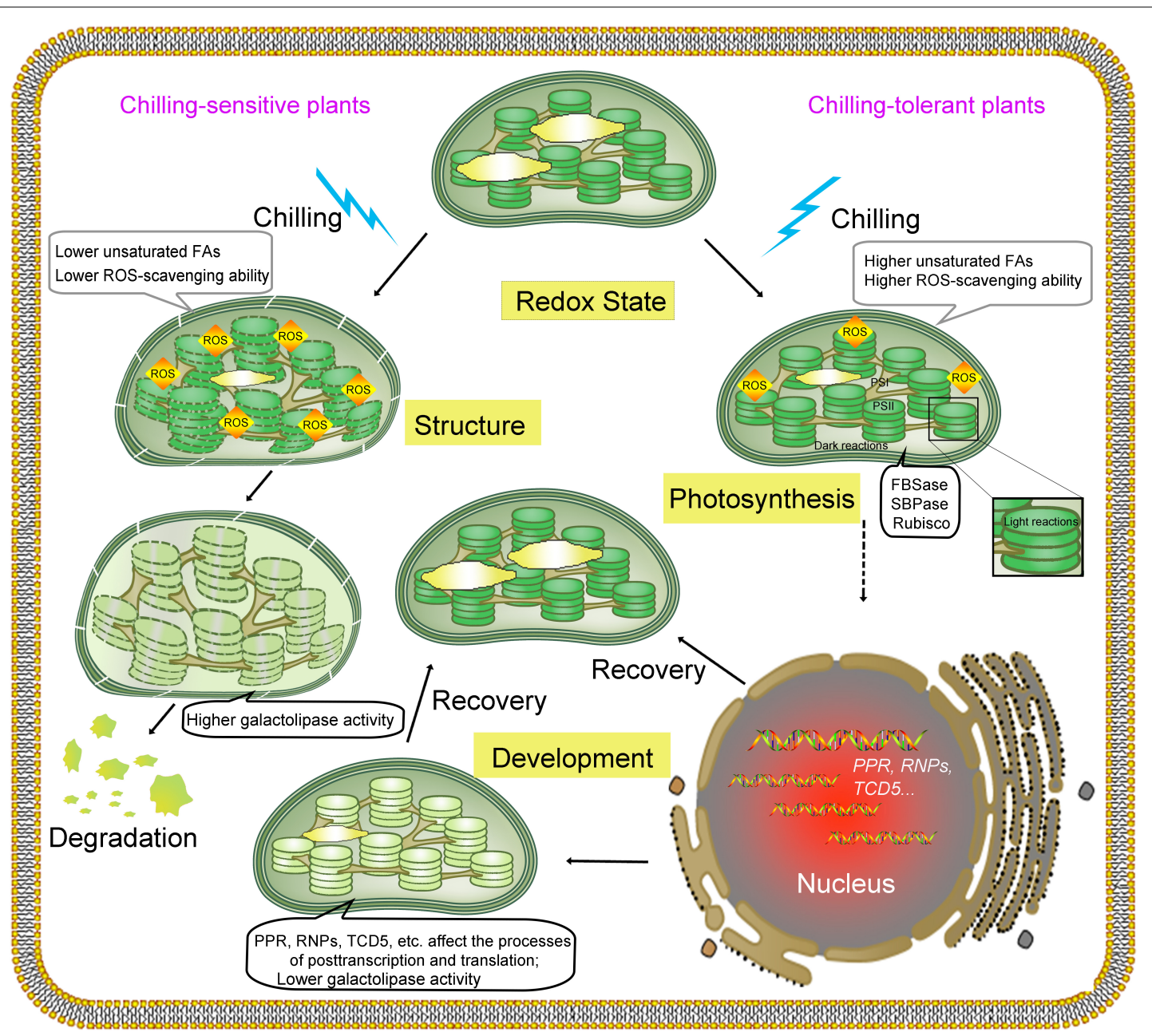

FIGURE 1 | Graphical representation of the effects of chilling on chloroplasts and corresponding responses. Chloroplasts are among the first organelles to sense low temperature, and low temperatures cause an array of changes to chloroplasts. Low temperatures change the membrane state and enzyme activities in chloroplasts, reducing the efficiency of photosynthesis (photoinhibition in PSI and PSII and affecting the Calvin cycle) and leading to the excess production of ROS. On one hand, ROS cause oxidative damage to molecules, including proteins, nucleic acids and lipids. On the other hand, the accumulation of ROS acts as a signal that activates acclimation mechanisms and regulates gene expression in the nucleus and chloroplasts. The activities of two rate-limiting enzymes involved in the Calvin cycle, fructose-1,6-bisphosphatase (FBPase) and sedoheptulose-1,7-bisphosphatase (SBPase), decrease under low temperature. As chilling time increases, the numbers and sizes of the starch grains decrease. In chilling-sensitive plants with lower levels of unsaturated FAs and reduced ROS-scavenging ability, the thylakoid morphology is abnormal, and the membrane structure is disrupted by excess ROS, which is accompanied by significantly higher galactolipase activity; In addition, the morphology of chloroplasts is altered, and the chlorophyll content decreases, which leads to the dysfunction and degradation of chloroplasts. In chilling-tolerant plants, the ROS-scavenging system is activated to protect the membrane against oxidative damage and initiate cold acclimation. Several nuclear genes, such as PPR, RNPS, and TCD5, involved in RNA processing in chloroplasts are regulated at the transcriptional level or the posttranscriptional level, and accompany with lower galactolipase activity. Altogether, these changes help plants better adapt to lower temperatures with or without chlorophyll content change in recovery stage. "Structure" indicates the structure of the chloroplast membrane; "Development" indicates chloroplast development; "Photosynthesis" indicates the photosynthesis system; and "Redox State" indicates the redox state in chloroplasts. 
mutants with a vitamin-E-deficiency are sensitive to chilling, due to the defective export of photoassimilate (Stitt and Hurry, 2002; Maeda et al., 2006). Overall, the underlying mechanisms that mediate the levels of $R B P, T C D 5$ and other genes with roles in chloroplast development are not well understood.

\section{CONCLUSION AND PERSPECTIVES}

Low temperatures represent an important environmental factor affecting plant growth and development. Nonetheless, under these circumstances, plants need to not only survive but also grow and develop. Chloroplasts are the key organelles in which energy is transformed, and they can sense cold signals. Chloroplast redox imbalance, membrane fluidity, as well as phytochromes are thought to be temperature-sensitive indicators. Multiple sensors maybe simultaneously take part in the process of perceiving low temperature. Low temperature induces chloroplast relocation and the cold-avoidance response in a short time. The phyB photoreceptor and phototropins participate in both temperature and light perception, which may further alter cytosolic $\mathrm{Ca}^{2+}$ levels. It would be interesting to study the underlying mechanisms that photoreceptors cause an increase in cytoplasmic calcium and transfer signals in low temperature.

A constitutive low temperature has deleterious effects on plant growth and development. Upon chilling, the activities of enzymes involved in photosynthesis (such as those involved in photoinhibition and the Calvin cycle) and the fluidity of the membrane decrease, affecting the ability of protein complexes to function normally in photosynthesis systems and causing decreased photosynthesis. Once an energy metabolic imbalance occurs, ROS are generated and can accumulate in chloroplasts. ROS, which are oxidative stresses, can destroy the integrity of the membrane (cold-sensitive plants exhibit serious injury

\section{REFERENCES}

Allen, D. J., and Ort, D. R. (2001). Impacts of chilling temperatures on photosynthesis in warm-climate plants. Trends Plant Sci. 6, 36-42. doi: 10.1016/ S1360-1385(00)01808-2

Byrd, G. T., Ort, D. R., and Ogren, W. L. (1995). The effects of chilling in the light on ribulose-1,5-bisphosphate carboxylase/oxygenase activation in tomato (Lycopersicon esculentum Mill.). Plant Physiol. 107, 585-591. doi: 10.1104/pp. 107.2.585

Chen, M., and Thelen, J. J. (2013). ACYL-LIPID DESATURASE2 is required for chilling and freezing tolerance in Arabidopsis. Plant Cell 25, 1430-1444. doi: 10.1105/tpc.113.111179

Chinnusamy, V., Zhu, J., and Zhu, J. K. (2007). Cold stress regulation of gene expression in plants. Trends Plant Sci. 12, 444-451. doi: 10.1016/j.tplants.2007. 07.002

Choi, S. M., Jeong, S. W., Jeong, W. J., Kwon, S. Y., Chow, W. S., and Park, Y.I. (2002). Chloroplast $\mathrm{Cu} / \mathrm{Zn}$-superoxide dismutase is a highly sensitive site in cucumber leaves chilled in the light. Planta 216, 315-324. doi: 10.1007/s00425002-0852-Z

Cronan, J. E., and Roughan, P. G. (1987). Fatty acid specificity and selectivity of the chloroplast $s n$-glycerol 3-phosphate acyltransferase of the Chilling Sensitive plant, Amaranthus lividus. Plant Physiol. 83, 676-680. doi: 10.1104/pp.83.3.676

Cui, X., Wang, Y., Wu, J., Han, X., Gu, X., Lu, T., et al. (2018). The RNA editing factor DUA1 is crucial to chloroplast development and death); additionally, ROS can stimulate the enhancement of ROS-scavenging activities in chloroplasts. Plants must adjust themselves to adapt to ambient temperature. An important step is the retrograde communication between the chloroplast and the nucleus. ROS also act as signals that regulate the transcription and posttranscriptional processing of photosynthesis-related genes in the chloroplast and nucleus to repair or regenerate damaged proteins, maintaining photosynthetic efficiency as much as possible (Pfannschmidt, 2003). The modification of gene transcription, protein translation and transportation to repair chilling-induced damage and induce acclimation to low temperatures leads to changes in chloroplast development, including changes in the size and number of chloroplasts and chlorophyll content. Finally, cold-resistant plants exhibit changes in growth and development to adapt to environmental stress (Figure 1). Chloroplasts play an important role in the process of plant adaptation to low temperature. During this process, plants need to coordinate the relationship between low-temperature adaptation and photosynthetic efficiency in order to obtain better growth and more production. Therefore, there is a trade-off between chilling tolerance and photosynthesis.

\section{AUTHOR CONTRIBUTIONS}

$\mathrm{XL}$ and FB wrote the review. All authors read and approved the final manuscript.

\section{FUNDING}

This work was supported by the Fundamental Research Funds for the Central Universities (No. 2016ZCQ02), the National Natural Science Foundation of China (31501090), and the Fundamental Research Funds for the Central Universities (No. 2017ZY23).

at low temperature in rice. New Phytol. doi: 10.1111/nph.15448 [Epub ahead of print].

D'Angeli, S., and Altamura, M. M. (2016). Unsaturated lipids change in olive tree drupe and seed during fruit development and in response to coldstress and acclimation. Int. J. Mol. Sci. 17:E1889. doi: 10.3390/ijms171 11889

Degenkolbe, T., Giavalisco, P., Zuther, E., Seiwert, B., Hincha, D. K., and Willmitzer, L. (2012). Differential remodeling of the lipidome during cold acclimation in natural accessions of Arabidopsis thaliana. Plant J. 72, 972-982. doi: $10.1111 /$ tpj.12007

Ding, S., Lei, M., Lu, Q., Zhang, A., Yin, Y., Wen, X., et al. (2012). Enhanced sensitivity and characterization of photosystem II in transgenic tobacco plants with decreased chloroplast glutathione reductase under chilling stress. Biochim. Biophys. Acta Bioenerget. 1817, 1979-1991. doi: 10.1016/j.bbabio.2012.06.003

Duan, M., Feng, H.-L., Wang, L.-Y., Li, D., and Meng, Q.-W. (2012). Overexpression of thylakoidal ascorbate peroxidase shows enhanced resistance to chilling stress in tomato. J. Plant Physiol. 169, 867-877. doi: 10.1016/j.jplph. 2012.02.012

Exposito-Rodriguez, M., Laissue, P. P., Yvon-Durocher, G., Smirnoff, N., and Mullineaux, P. M. (2017). Photosynthesis-dependent $\mathrm{H}_{2} \mathrm{O}_{2}$ transfer from chloroplasts to nuclei provides a high-light signalling mechanism. Nat. Commun. 8:49. doi: 10.1038/s41467-017-00074-w

Fedoroff, N. (2006). Redox regulatory mechanisms in cellular stress responses. Ann. Bot. 98, 289-300. doi: 10.1093/aob/mcl128 
Foreman, J., Demidchik, V., Bothwell, J. H., Mylona, P., Miedema, H., Torres, M. A., et al. (2003). Reactive oxygen species produced by NADPH oxidase regulate plant cell growth. Nature 422, 442-446. doi: 10.1038/nature01485

Foyer, C. H., and Noctor, G. (2005). Redox homeostasis and antioxidant signaling: a metabolic interface between stress perception and physiological responses. Plant Cell 17, 1866-1875. doi: 10.1105/tpc.105.033589

Foyer, C. H., and Noctor, G. (2009). Redox regulation in photosynthetic organisms: signaling, acclimation, and practical implications. Antioxid. Redox Signal. 11, 861-905. doi: 10.1089/ars.2008.2177

Fujii, Y., Tanaka, H., Konno, N., Ogasawara, Y., Hamashima, N., Tamura, S., et al. (2017). Phototropin perceives temperature based on the lifetime of its photoactivated state. Proc. Natl. Acad. Sci. U.S.A. 114, 9206-9211. doi: 10.1073/ pnas. 1704462114

Garstka, M., Venema, J. H., Rumak, I., Gieczewska, K., Rosiak, M., KoziolLipinska, J., et al. (2007). Contrasting effect of dark-chilling on chloroplast structure and arrangement of chlorophyll - protein complexes in pea and tomato: plants with a different susceptibility to non-freezing temperature. Planta 226, 1165-1181. doi: 10.1007/s00425-007-0562-7

Gong, X., Su, Q., Lin, D., Jiang, Q., Xu, J., Zhang, J., et al. (2014). The rice OsV4 encoding a novel pentatricopeptide repeat protein is required for chloroplast development during the early leaf stage under cold stress. J. Integr. Plant Biol. 56, 400-410. doi: 10.1111/jipb.12138

Greer, D. H., Berry, J. A., and Bjorkman, O. (1986). Photoinhibition of photosynthesis in intact bean leaves: role of light and temperature, and requirement for chloroplast-protein synthesis during recovery. Planta 168, 253-260. doi: 10.1007/BF00402971

Gu, L., Xu, T., Lee, K., Lee, K. H., and Kang, H. (2014). A chloroplast-localized DEAD-box RNA helicaseAtRH3 is essential for intron splicing and plays an important role in the growth and stress response in Arabidopsis thaliana. Plant Physiol. Biochem. 82, 309-318. doi: 10.1016/j.plaphy.2014.07.006

Gu, Y., He, L., Zhao, C., Wang, F., Yan, B., Gao, Y., et al. (2017). Biochemical and transcriptional regulation of membrane lipid metabolism in maize leaves under low temperature. Front. Plant Sci. 8:2053. doi: 10.3389/fpls.2017.02053

Guy, C. L., Huber, J. L., and Huber, S. C. (1992). Sucrose phosphate synthase and sucrose accumulation at low temperature. Plant Physiol. 100, 502-508. doi: $10.1104 /$ pp.100.1.502

Hodgson, R. A. J., Orr, G. R., and Raison, J. K. (1987). Inhibition of photosynthesis by chilling in the light. Plant Sci. 49, 75-79. doi: 10.1016/0168-9452(87)90002-1

Hola, D., Kutik, J., Kocova, M., and Rothova, O. (2008). Low-temperature induced changes in the ultrastructure of maize mesophyll chloroplasts strongly depend on the chilling pattern/intensity and considerably differ among inbred and hybrid genotypes. Photosynthetica 46, 329-338. doi: 10.1007/s11099-0080061-5

Holaday, A. S., Martindale, W., Alred, R., Brooks, A. L., and Leegood, R. C. (1992). Changes in activities of enzymes of carbon metabolism in leaves during exposure of plants to low temperature. Plant Physiol. 98, 1105-1114. doi: 10. 1104/pp.98.3.1105

Hu, W. H., Song, X. S., Shi, K., Xia, X. J., Zhou, Y. H., and Yu, J. Q. (2008). Changes in electron transport, superoxide dismutase and ascorbate peroxidase isoenzymes in chloroplasts and mitochondria of cucumber leaves as influenced by chilling. Photosynthetica 46, 581-588. doi: 10.1007/s11099-008-0098-5

Huang, W., Yang, Y. J., Hu, H., and Zhang, S. B. (2016). Moderate photoinhibition of photosystem II protects photosystem I from photodamage at chilling stress in tobacco leaves. Front. Plant Sci. 7:182. doi: 10.3389/fpls.2016.00182

Humbeck, K., Kloppstech, K., and Krupinska, K. (1994). Expression of early light-inducible proteins in flag leaves of field-grown barley. Plant Physiol. 105, 1217-1222. doi: 10.1104/pp.105.4.1217

Hurry, V. M., Malmberg, G., Gardestrom, P., and Oquist, G. (1994). Effects of a short-term shift to low temperature and of long-term cold hardening on photosynthesis and Ribulose-1,5-Bisphosphate carboxylase/oxygenase and sucrose phosphate synthase activity in leaves of winter rye (Secale cereale L.). Plant Physiol. 106, 983-990. doi: 10.1104/pp.106. 3.983

Hutchison, R. S., Groom, Q., and Ort, D. R. (2000). Differential effects of chillinginduced photooxidation on the redox regulation of photosynthetic enzymes. Biochemistry 39, 6679-6688. doi: 10.1021/bi0001978

Jing, L. W., Chen, S. H., Guo, X. L., Zhang, H., and Zhao, Y. X. (2006). Overexpression of a chloroplast-located peroxiredoxin q gene, SsPrxQ, increases the salt and low-temperature tolerance of Arabidopsis. J. Integr. Plant Biol. 48, 1244-1249. doi: 10.1111/j.1744-7909.2006.00357.x

Jung, J. H., Domijan, M., Klose, C., Biswas, S., Ezer, D., Gao, M., et al. (2016). Phytochromes function as thermosensors in Arabidopsis. Science 354, 886-889. doi: 10.1126/science.aaf6005

Kaniuga, Z. (2008). Chilling response of plants: importance of galactolipase, free fatty acids and free radicals. Plant Biol. 10, 171-184. doi: 10.1111/j.1438-8677. 2007.00019.x

Kaniuga, Z., and Michalski, W. (1978). Photosynthetic apparatus in chilling-sensitive plants : II. Changes in free fatty acid composition and photoperoxidation in chloroplasts following cold storage and illumination of leaves in relation to Hill reaction activity. Planta 140, 129-136. doi: $10.1007 /$ bf00384911

Kaniuga, Z., Z Symbol See Text Bek, J., and Michalski, W. P. (1979). Photosynthetic apparatus in chilling-sensitive plants : VI. Cold and dark-induced changes in chloroplast superoxide dismutase activity in relation to loosely-bound manganese content. Planta 145, 145-150. doi: 10.1007/bf00388710

Karim, S., Alezzawi, M., Garcia-Petit, C., Solymosi, K., Khan, N. Z., Lindquist, E., et al. (2014). A novel chloroplast localized Rab GTPase protein CPRabA5e is involved in stress, development, thylakoid biogenesis and vesicle transport in Arabidopsis. Plant Mol. Biol. 84, 675-692. doi: 10.1007/s11103-013-0161-x

Khodakovskaya, M., McAvoy, R., Peters, J., Wu, H., and Li, Y. (2006). Enhanced cold tolerance in transgenic tobacco expressing a chloroplast omega-3 fatty acid desaturase gene under the control of a cold-inducible promoter. Planta 223, 1090-1100. doi: 10.1007/s00425-005-0161-4

Kim, C., Meskauskiene, R., Zhang, S., Lee, K. P., Lakshmanan Ashok, M., Blajecka, K., et al. (2012). Chloroplasts of Arabidopsis are the source and a primary target of a plant-specific programmed cell death signaling pathway. Plant Cell 24, 3026-3039. doi: 10.1105/tpc.112.100479

Kim, Y., Kwon, S.-Y., Kwak, S.-S., and Bang, J.-W. (2003). Photosynthetic efficiency in transgenic tobacco plants expressing both CuZnSOD and APX in chloroplasts against oxidative stress caused by highlight and chilling. J. Plant Biotechnol. 30, 399-403. doi: 10.5010/JPB.2003.30.4.399

Kingston-Smith, A. H., Harbinson, J., Williams, J., and Foyer, C. H. (1997). Effect of chilling on carbon assimilation, enzyme activation, and photosynthetic electron transport in the absence of photoinhibition in maize leaves. Plant Physiol. 114, 1039-1046. doi: 10.1104/pp.114.3.1039

Kodama, Y., Tsuboi, H., Kagawa, T., and Wada, M. (2008). Low temperatureinduced chloroplast relocation mediated by a blue light receptor, phototropin 2, in fern gametophytes. J. Plant Res. 121, 441-448. doi: 10.1007/s10265-0080165-9

Kong, F., Deng, Y., Zhou, B., Wang, G., Wang, Y., and Meng, Q. (2014). A chloroplast-targeted DnaJ protein contributes to maintenance of photosystem II under chilling stress. J. Exp. Bot. 65, 143-158. doi: $10.1093 /$ jxb/ert357

Kratsch, H., and Wise, R. R. (2000). The ultrastructure of chilling stress. Plant Cell Environ. 23, 337-350. doi: 10.1046/j.1365-3040.2000.00560.x

Kudoh, H., and Sonoike, K. (2002). Irreversible damage to photosystem I by chilling in the light: cause of the degradation of chlorophyll after returning to normal growth temperature. Planta 215, 541-548. doi: 10.1007/s00425-0020790-9

Kupsch, C., Ruwe, H., Gusewski, S., Tillich, M., Small, I., and SchmitzLinneweber, C. (2012). Arabidopsis chloroplast RNA binding proteins CP31A and CP29A associate with large transcript pools and confer cold stress tolerance by influencing multiple chloroplast RNA processing steps. Plant Cell 24, 42664280. doi: 10.1105/tpc.112.103002

Kurepin, L. V., Dahal, K. P., Savitch, L. V., Singh, J., Bode, R., Ivanov, A. G., et al. (2013). Role of CBFs as integrators of chloroplast redox, phytochrome and plant hormone signaling during cold acclimation. Int. J. Mol. Sci. 14, 12729-12763. doi: 10.3390/ijms140612729

Kusumi, K., Sakata, C., Nakamura, T., Kawasaki, S., Yoshimura, A., and Iba, K. (2011). A plastid protein NUS1 is essential for build-up of the genetic system for early chloroplast development under cold stress conditions. Plant J. 68, 1039-1050. doi: 10.1111/j.1365-313X.2011. 04755.x

Kutik, J., Hola, D., Kocova, M., Rothova, O., Haisel, D., Wilhelmova, N., et al. (2004). Ultrastructure and dimensions of chloroplasts in leaves of three maize (Zea mays L.) inbred lines and their F-1 hybrids grown under moderate 
chilling stress. Photosynthetica 42, 447-455. doi: 10.1023/B:PHOT.0000046165. 15048.a4

Laloi, C., Apel, K., and Danon, A. (2004). Reactive oxygen signalling: the latest news. Curr. Opin. Plant Biol. 7, 323-328. doi: 10.1016/j.pbi.2004. 03.005

Lee, K. P., Kim, C., Landgraf, F., and Apel, K. (2007). EXECUTER1- and EXECUTER2-dependent transfer of stress-related signals from the plastid to the nucleus of Arabidopsis thaliana. Proc. Natl. Acad. Sci. U.S.A. 104, 10270-10275. doi: 10.1073/pnas.0702061104

Legris, M., Klose, C., Burgie, E. S., Rojas, C. C., Neme, M., Hiltbrunner, A., et al. (2016). Phytochrome B integrates light and temperature signals in Arabidopsis. Science 354, 897-900. doi: 10.1126/science.aaf5656

Li, D.-M., Guo, Y.-K., Li, Q., Zhang, J., Wang, X.-J., and Bai, J.-G. (2012). The pretreatment of cucumber with methyl jasmonate regulates antioxidant enzyme, activities and protects chloroplast and mitochondrial ultrastructure in chilling-stressed leaves. Sci. Hortic. 143, 135-143. doi: 10.1016/j.scienta.2012. 06.020

Li, H. M., and Yu, C. W. (2018). Chloroplast galactolipids: the link between photosynthesis, chloroplast shape, jasmonates, phosphate starvation and freezing tolerance. Plant Cell Physiol. 59, 1128-1134. doi: 10.1093/pcp/ pcy088

Li, X., Hao, C., Zhong, J., Liu, F., Cai, J., Wang, X., et al. (2015). Mechanostimulated modifications in the chloroplast antioxidant system and proteome changes are associated with cold response in wheat. BMC Plant Biol. 15:219. doi: 10.1186/s12870-015-0610-6

Lim, S., Kim, Y.-H., Kim, S.-H., Kwon, S.-Y., Lee, H.-S., Kim, J.-S., et al. (2007). Enhanced tolerance of transgenic sweet potato plants that express both CuZnSOD and APX in chloroplasts to methyl viologen-mediated oxidative stress and chilling. Mol. Breed. 19, 227-239. doi: 10.1007/s11032-0069051-0

Liu, X., Rodermel, S. R., and Yu, F. (2010). A var2 leaf variegation suppressor locus, SUPPRESSOR OF VARIEGATION3, encodes a putative chloroplast translation elongation factor that is important for chloroplast development in the cold. BMC Plant Biol. 10:287. doi: 10.1186/1471-2229$10-287$

Liu, X. Y., Li, B., Yang, J. H., Sui, N., Yang, X. M., and Meng, Q. W. (2008). Overexpression of tomato chloroplast omega-3 fatty acid desaturase gene alleviates the photoinhibition of photosystems 2 and 1 under chilling stress. Photosynthetica 46, 185-192. doi: 10.1007/s11099-008-0030-z

Lyons, J. M. (1973). Chilling injury in plants. Annu. Rev. Plant Physiol. 24, 445-466. doi: 10.1146/annurev.pp.24.060173.002305

Maeda, H., Song, W., Sage, T. L., and DellaPenna, D. (2006). Tocopherols play a crucial role in low-temperature adaptation and phloem loading in Arabidopsis. Plant Cell 18, 2710-2732. doi: 10.1105/tpc.105.039404

Mignolet-Spruyt, L., Xu, E., Idanheimo, N., Hoeberichts, F. A., Muhlenbock, P., Brosche, M., et al. (2016). Spreading the news: subcellular and organellar reactive oxygen species production and signalling. J. Exp. Bot. 67, 3831-3844. doi: 10.1093/jxb/erw080

Miller, G., Shulaev, V., and Mittler, R. (2008). Reactive oxygen signaling and abiotic stress. Physiol. Plant. 133, 481-489. doi: 10.1111/j.1399-3054.2008.01090.x

Miller, G., Suzuki, N., Ciftci-Yilmaz, S., and Mittler, R. (2010). Reactive oxygen species homeostasis and signalling during drought and salinity stresses. Plant Cell Environ. 33, 453-467. doi: 10.1111/j.1365-3040.2009.02041.x

Mittler, R. (2002). Oxidative stress, antioxidants and stress tolerance. Trends Plant Sci. 7, 405-410. doi: 10.1016/S1360-1385(02)02312-9

Mittler, R., Vanderauwera, S., Gollery, M., and Van Breusegem, F. (2004). Reactive oxygen gene network of plants. Trends Plant Sci. 9, 490-498. doi: 10.1016/j. tplants.2004.08.009

Moon, B. Y., Higashi, S., Gombos, Z., and Murata, N. (1995). Unsaturation of the membrane lipids of chloroplasts stabilizes the photosynthetic machinery against low-temperature photoinhibition in transgenic tobacco plants. Proc. Natl. Acad. Sci. U.S.A. 92, 6219-6223. doi: 10.1073/pnas.92. 14.6219

Morita, R., Nakagawa, M., Takehisa, H., Hayashi, Y., Ichida, H., Usuda, S., et al. (2017). Heavy-ion beam mutagenesis identified an essential gene for chloroplast development under cold stress conditions during both early growth and tillering stages in rice. Biosci. Biotechnol. Biochem. 81, 271-282. doi: 10.1080/ 09168451.2016 .1249452
Mou, Z., Fan, W., and Dong, X. (2003). Inducers of plant systemic acquired resistance regulate NPR1 function through redox changes. Cell 113, 935-944. doi: 10.1016/S0092-8674(03)00429-X

Mullet, J. E. (1988). Chloroplast development and gene expression. Annu. Rev. Plant Physiol. Plant Mol. Biol. 39, 475-502. doi: 10.1146/annurev.pp.39.060188. 002355

Mullineaux, P. M., Exposito-Rodriguez, M., Laissue, P. P., and Smirnoff, N. (2018). ROS-dependent signalling pathways in plants and algae exposed to high light: comparisons with other eukaryotes. Free Radic. Biol. Med. 122, 52-64. doi: 10.1016/j.freeradbiomed.2018.01.033

Murata, N., Ishizaki-Nishizawa, O., Higashi, S., Hayashi, H., Tasaka, Y., and Nishida, I. (1992). Genetically engineered alteration in the chilling sensitivity of plants. Nature 356, 710-713. doi: 10.1038/356710a0

Musser, R. L., Thomas, S. A., Wise, R. R., Peeler, T. C., and Naylor, A. W. (1984). Chloroplast ultrastructure, chlorophyll fluorescence, and pigment composition in chilling-stressed soybeans. Plant Physiol. 74, 749-754. doi: 10.1104/pp.74.4. 749

Novitskaya, G. V., and Trunova, T. I. (2000). Relationship between cold resistance of plants and the lipid content of their chloroplast membranes. Dokl. Biochem. $371,50-52$.

Partelli, F. L., Batista-Santos, P., Scotti-Campos, P., Pais, I. P., Quartin, V. L., Vieira, H. D., et al. (2011). Characterization of the main lipid components of chloroplast membranes and cold induced changes in Coffea spp. Environ. Exp. Bot. 74, 194-204. doi: 10.1016/j.envexpbot.2011. 06.001

Peeler, T. C., and Naylor, A. W. (1988). A comparison of the effects of chilling on thylakoid electron transfer in Pea (Pisum sativum L.) and cucumber (Cucumis sativus L.). Plant Physiol. 86, 147-151. doi: 10.1104/pp. 86.1.147

Peoples, T. R., Koch, D. W., and Smith, S. C. (1978). Relationship between chloroplast membrane fatty acid composition and photosynthetic response to a chilling temperature in four alfalfa cultivars. Plant Physiol. 61, 472-473. doi: 10.1104/pp.61.3.472

Pfannschmidt, T. (2003). Chloroplast redox signals: how photosynthesis controls its own genes. Trends Plant Sci. 8, 33-41. doi: 10.1016/S1360-1385(02)00005-5

Pitzschke, A., Forzani, C., and Hirt, H. (2006). Reactive oxygen species signaling in plants. Antioxid. Redox Signal. 8, 1757-1764. doi: 10.1089/ars.2006. 8.1757

Popov, V. N., Antipina, O. V., Pchelkin, V. P., and Tsydendambaev, V. D. (2017). Changes in fatty acid composition of lipids in chloroplast membranes of tobacco plants during cold hardening. Russ. J. Plant Physiol. 64, 156-161. doi: $10.1134 / \mathrm{s} 1021443717010137$

Pribil, M., Labs, M., and Leister, D. (2014). Structure and dynamics of thylakoids in land plants. J. Exp. Bot. 65, 1955-1972. doi: 10.1093/jxb/ eru090

Routaboul, J. M., Fischer, S. F., and Browse, J. (2000). Trienoic fatty acids are required to maintain chloroplast function at low temperatures. Plant Physiol. 124, 1697-1705. doi: 10.1104/pp.124.4.1697

Saczynska, V., Kargul, J., and Kaniuga, Z. (1993). Discrimination between chillingsensitive and chilling-resistant plants based on measurements of free fatty acid accumulation and inactivation of oxygen evolution in aged chloroplasts. Acta Biochim. Pol. 40, 507-513.

Sakamoto, A., Sulpice, R., Hou, C. X., Kinoshita, M., Higashi, S. I., Kanaseki, T., et al. (2004). Genetic modification of the fatty acid unsaturation of phosphatidylglycerol in chloroplasts alters the sensitivity of tobacco plants to cold stress. Plant Cell Environ. 27, 99-105. doi: 10.1046/j.0016-8025.2003. 01131.x

Saropulos, A. S., and Drennan, D. S. H. (2007). Ultrastructural alterations in mesophyll and bundle sheath chloroplasts of two maize cultivars in response to chilling at high irradiance. Biol. Plant. 51, 690-698. doi: 10.1007/s10535-007$0144-3$

Sassenrath, G. F., Ort, D. R., and Portis, A. R. Jr. (1990). Impaired reductive activation of stromal bisphosphatases in tomato leaves following lowtemperature exposure at high light. Arch. Biochem. Biophys. 282, 302-308. doi: 10.1016/0003-9861(90)90121-E

Savitch, L. V., Barker-Astrom, J., Ivanov, A. G., Hurry, V., Oquist, G., Huner, N. P., et al. (2001). Cold acclimation of Arabidopsis thaliana results in incomplete recovery of photosynthetic capacity, associated with an increased reduction 
of the chloroplast stroma. Planta 214, 295-303. doi: 10.1007/s0042501 00622

Scotti-Campos, P., Pais, I. P., Partelli, F. L., Batista-Santos, P., and Ramalho, J. C. (2014). Phospholipids profile in chloroplasts of Coffea spp. genotypes differing in cold acclimation ability. J. Plant Physiol. 171, 243-249. doi: 10.1016/jblph. 2013.07.007

Shen, J. R., Terashima, I., and Katoh, S. (1990). Cause for dark, chilling-induced inactivation of photosynthetic oxygen-evolving system in cucumber leaves. Plant Physiol. 93, 1354-1357. doi: 10.1104/pp.93.4.1354

Shi, Y., Ding, Y., and Yang, S. (2018). Molecular regulation of CBF signaling in cold acclimation. Trends Plant Sci. 23, 623-637. doi: 10.1016/j.tplants.2018.04.002

Shu, D.-F., Wang, L.-Y., Duan, M., Deng, Y.-S., and Meng, Q.-W. (2011). Antisense-mediated depletion of tomato chloroplast glutathione reductase enhances susceptibility to chilling stress. Plant Physiol. Biochem. 49, 1228-1237. doi: 10.1016/j.plaphy.2011.04.005

Skupień, J., Wójtowicz, J., Kowalewska, Ł., Mazur, R., Garstka, M., Gieczewska, K., et al. (2017). Dark-chilling induces substantial structural changes and modifies galactolipid and carotenoid composition during chloroplast biogenesis in cucumber (Cucumis sativus L.) cotyledons. Plant Physiol. Biochem. 111, 107118. doi: 10.1016/j.plaphy.2016.11.022

Soliman, M. H., Alayafi, A. A. M., El Kelish, A. A., and Abu-Elsaoud, A. M. (2018). Acetylsalicylic acid enhance tolerance of Phaseolus vulgaris L. to chilling stress, improving photosynthesis, antioxidants and expression of cold stress responsive genes. Bot. Stud. 59:6. doi: 10.1186/s40529-018-0222-1

Somerville, C. (1995). Direct tests of the role of membrane lipid composition in low-temperature-induced photoinhibition and chilling sensitivity in plants and cyanobacteria. Proc. Natl. Acad. Sci. U.S.A. 92, 6215-6218. doi: 10.1073/pnas. 92.14.6215

Song, J., Wei, X. J., Shao, G. N., Sheng, Z. H., Chen, D. B., Liu, C. L., et al. (2014). The rice nuclear gene WLP1 encoding a chloroplast ribosome L13 protein is needed for chloroplast development in rice grown under low temperature conditions. Plant Mol. Biol. 84, 301-314. doi: 10.1007/s11103-013-0134-0

Sonoike, K., Terashima, I., Iwaki, M., and Itoh, S. (1995). Destruction of photosystem I iron-sulfur centers in leaves of Cucumis sativus L. by weak illumination at chilling temperatures. FEBS Lett. 362, 235-238. doi: 10.1016/ 0014-5793(95)00254-7

Stitt, M., and Hurry, V. (2002). A plant for all seasons: alterations in photosynthetic carbon metabolism during cold acclimation in Arabidopsis. Curr. Opin. Plant Biol. 5, 199-206. doi: 10.1016/S1369-5266(02)00258-3

Strand, A., Hurry, V., Gustafsson, P., and Gardestrom, P. (1997). Development of Arabidopsis thaliana leaves at low temperatures releases the suppression of photosynthesis and photosynthetic gene expression despite the accumulation of soluble carbohydrates. Plant J. 12, 605-614. doi: 10.1046/j.1365-313X.1997. 00605.x

Strand, A., Hurry, V., Henkes, S., Huner, N., Gustafsson, P., Gardestrom, P., et al. (1999). Acclimation of Arabidopsis leaves developing at low temperatures. Increasing cytoplasmic volume accompanies increased activities of enzymes in the Calvin cycle and in the sucrose-biosynthesis pathway. Plant Physiol. 119, 1387-1398. doi: 10.1104/pp.119.4.1387

Sun, J., Zheng, T., Yu, J., Wu, T., Wang, X., Chen, G., et al. (2017). TSV, a putative plastidic oxidoreductase, protects rice chloroplasts from cold stress during development by interacting with plastidic thioredoxin Z. New Phytol. 215, 240-255. doi: 10.1111/nph.14482

Suzuki, N., Koussevitzky, S., Mittler, R., and Miller, G. (2012). ROS and redox signalling in the response of plants to abiotic stress. Plant Cell Environ. 35, 259-270. doi: 10.1111/j.1365-3040.2011.02336.x

Takahashi, M., and Asada, K. (1988). Superoxide production in aprotic interior of chloroplast thylakoids. Arch. Biochem. Biophys. 267, 714-722. doi: 10.1016/ 0003-9861(88)90080-X

Takahashi, S., and Murata, N. (2008). How do environmental stresses accelerate photoinhibition? Trends Plant Sci. 13, 178-182. doi: 10.1016/j.tplants.2008. 01.005

Teicher, H. B., Møller, B. L., and Scheller, H. V. (2000). Photoinhibition of photosystem I in field-grown barley (Hordeum vulgare L.): induction, recovery and acclimation. Photosynth. Res. 64, 53-61. doi: 10.1023/A:102652430 2191

Terashima, I., Funayama, S., and Sonoike, K. (1994). The site of photoinhibition in leaves of Cucumis sativus L. at low temperatures is photosystem
I, not photosystem II. Planta 193, 300-306. doi: 10.1007/bf0019 2544

Terashima, I., Huang, L. K., and Osmond, C. B. (1989). Effects of leaf chilling on thylakoid functions, measured at room temperature, in Cucumis sativus L. and Oryza sativa L. Plant Cell Physiol. 30, 841-850. doi: 10.1093/oxfordjournals.pcp. a077814

Terashima, I., Kashino, Y., and Katoh, S. (1991a). Exposure of leaves of Cucumis sativus L. to low temperatures in the light causes uncoupling of thylakoids I. Studies with isolated thylakoids. Plant Cell Physiol. 32, 1267-1274.

Terashima, I., Sonoike, K., Kawazu, T., and Katoh, S. (1991b). Exposure of leaves of Cucumis sativus L. to low temperatures in the light causes uncoupling of thylakoids II. Non-destructive measurements with intact leaves. Plant Cell Physiol. 32, 1267-1274.

Theocharis, A., Clément, C., and Barka, E. A. (2012). Physiological and molecular changes in plants grown at low temperatures. Planta 235, 1091-1105. doi: 10.1007/s00425-012-1641-y

Tjus, S. E., Moller, B. L., and Scheller, H. V. (1998). Photosystem I is an early target of photoinhibition in barley illuminated at chilling temperatures. Plant Physiol. 116, 755-764. doi: 10.1104/pp.116.2.755

Tokuhisa, J. G., Vijayan, P., and Feldmann, K. A. (1998). Chloroplast development at low temperatures requires a homolog of DIM1, a yeast gene encoding the $18 \mathrm{~S}$ rRNA dimethylase. Plant Cell 10, 699-711. doi: 10.1105/tpc.10.5.699

van Buer, J., Cvetkovic, J., and Baier, M. (2016). Cold regulation of plastid ascorbate peroxidases serves as a priming hub controlling ROS signaling in Arabidopsis thaliana. BMC Plant Biol. 16:163. doi: 10.1186/s12870-016-0856-7

Venzhik, Y., Talanova, V., and Titov, A. (2016). The effect of abscisic acid on cold tolerance and chloroplasts ultrastructure in wheat under optimal and cold stress conditions. Acta Physiol. Plant. 38:63. doi: 10.1007/s11738-016-2082-1

Venzhik, Y. V., Titov, A. F., Talanova, V. V., and Miroslavov, E. A. (2014). Ultrastructure and functional activity of chloroplasts in wheat leaves under root chilling. Acta Physiol. Plant. 36, 323-330. doi: 10.1007/s11738-0131413-8

Wang, S., Bai, G., Wang, S., Yang, L., Yang, F., Wang, Y., et al. (2016). Chloroplast RNA-binding protein RBD1 promotes chilling tolerance through 23S rRNA processing in Arabidopsis. PLoS Genet. 12:e1006027. doi: 10.1371/journal.pgen. 1006027

Wang, Y., Zhang, J. H., Shi, X. L., Peng, Y., Li, P., Lin, D. Z., et al. (2016). Temperature-sensitive albino gene TCD5, encoding a monooxygenase, affects chloroplast development at low temperatures. J. Exp. Bot. 67, 5187-5202. doi: 10.1093/jxb/erw287

$\mathrm{Wu}$, J., and Browse, J. (1995). Elevated levels of high-melting-point phosphatidylglycerols do not induce chilling sensitivity in an Arabidopsis mutant. Plant Cell 7, 17-27. doi: 10.1105/tpc.7.1.17

Wu, J., Lightner, J., Warwick, N., and Browse, J. (1997). Low-temperature damage and subsequent recovery of fab1 mutant Arabidopsis exposed to 2 degrees C. Plant Physiol. 113, 347-356. doi: 10.1104/pp.113.2.347

Wu, L., Wu, J., Liu, Y., Gong, X., Xu, J., Lin, D., et al. (2016). The rice pentatricopeptide repeat gene TCD10 is needed for chloroplast development under cold stress. Rice 9:67. doi: 10.1186/s12284-0160134-1

Wu, X. X., Ding, H. D., Chen, J. L., Zhu, Z. W., and Zha, D. S. (2015). Exogenous spray application of 24-epibrassinolide induced changes in photosynthesis and anti-oxidant defences against chilling stress in eggplant (Solanum melongena L.) seedlings. J. Hortic. Sci. Biotechnol. 90, 217-224. doi: 10.1080/14620316.2015. 11513175

Xiao, Y., Savchenko, T., Baidoo, E. E., Chehab, W. E., Hayden, D. M., Tolstikov, V., et al. (2012). Retrograde signaling by the plastidial metabolite MEcPP regulates expression of nuclear stress-response genes. Cell 149, 1525-1535. doi: 10.1016/ j.cell.2012.04.038

Xu, T., Sy, N. D., Lee, H. J., Kwak, K. J., Gu, L., Kim, J. I., et al. (2014). Functional characterization of a chloroplast-targeted RNA-binding protein CRP1 in Arabidopsis thaliana under abiotic stress conditions. J. Plant Biol. 7, 349-356. doi: 10.1007/s12374-014-0372-y

Zbierzak, A. M., Porfirova, S., Griebel, T., Melzer, M., Parker, J. E., and Dörmann, P. (2013). A TIR-NBS protein encoded by Arabidopsis Chilling Sensitive 1 (CHS1) limits chloroplast damage and cell death at low temperature. Plant J. 75, 539-552. doi: 10.1111/tpj.12219 
Zhang, J., Yuan, H., Yang, Y., Fish, T., Lyi, S. M., Thannhauser, T. W., et al. (2016). Plastid ribosomal protein S5 is involved in photosynthesis, plant development, and cold stress tolerance in Arabidopsis. J. Exp. Bot. 67, 2731-2744. doi: 10.1093/ jxb/erw106

Zhang, N., and Portis, A. R. Jr. (1999). Mechanism of light regulation of Rubisco: a specific role for the larger Rubisco activase isoform involving reductive activation by thioredoxin-f. Proc. Natl. Acad. Sci. U.S.A. 96, 9438-9443. doi: 10.1073/pnas.96.16.9438

Zhang, S., and Scheller, H. V. (2004). Photoinhibition of photosystem $\mathrm{I}$ at chilling temperature and subsequent recovery in Arabidopsis thaliana. Plant Cell Physiol. 45, 1595-1602. doi: 10.1093/pcp/ pch180

Zhang, Z. S., Yang, C., Gao, H. Y., Zhang, L. T., Fan, X. L., and Liu, M. J. (2014). The higher sensitivity of PSI to ROS results in lower chilling-light tolerance of photosystems in young leaves of cucumber. J. Photochem. Photobiol. B 137, 127-134. doi: 10.1016/j.jphotobiol.2013.12.012

Zhao, H., Ye, L., Wang, Y., Zhou, X., Yang, J., Wang, J., et al. (2016). Melatonin increases the chilling tolerance of chloroplast in cucumber seedlings by regulating photosynthetic electron flux and the ascorbateglutathione cycle. Front. Plant Sci. 7:1814. doi: 10.3389/fpls.2016. 01814
Zhou, Y. H., Yu, J. Q., Mao, W. H., Huang, L. F., Song, X. S., and Nogues, S. (2006). Genotypic variation of rubisco expression, photosynthetic electron flow and antioxidant metabolism in the chloroplasts of chill-exposed cucumber plants. Plant Cell Physiol. 47, 192-199. doi: 10.1093/pcp/pci234

Zhu, J. K. (2016). Abiotic stress signaling and responses in plants. Cell 167, 313-324. doi: 10.1016/j.cell.2016.08.029

Zhuang, K., Kong, F., Zhang, S., Meng, C., Yang, M., Liu, Z., et al. (2018). Whirly1 enhances tolerance to chilling stress in tomato via protection of photosystem II and regulation of starch degradation. New Phytol. doi: 10.1111/nph.15532 [Epub ahead of print].

Conflict of Interest Statement: The authors declare that the research was conducted in the absence of any commercial or financial relationships that could be construed as a potential conflict of interest.

Copyright (c) $2018 \mathrm{Liu}$, Zhou, Xiao and Bao. This is an open-access article distributed under the terms of the Creative Commons Attribution License (CC BY). The use, distribution or reproduction in other forums is permitted, provided the original author(s) and the copyright owner(s) are credited and that the original publication in this journal is cited, in accordance with accepted academic practice. No use, distribution or reproduction is permitted which does not comply with these terms. 